\title{
The Role of New Ferrite on Retained Austenite Stabilization in Al-TRIP Steels
}

\author{
Manuel GOMEZ, ${ }^{1)}$ C. Isaac GARCIA ${ }^{2)}$ and Anthony J. DEARDO ${ }^{2,3)}$ \\ 1) Formerly at BAMPRI, University of Pittsburgh, Now at National Center for Metallurgical Research (CENIM-CSIC), Avda. \\ Gregorio del Amo 8, 28040 Madrid, Spain. E-mail: mgomez@cenim.csic.es \\ 2) Basic Metals Processing Research Institute (BAMPRI), Mechanical Engineering and Materials Science Department, \\ University of Pittsburgh, 848 Benedum Hall, Pittsburgh, PA 15261, USA. E-mail: cigarcia@pitt.edu, deardo@pitt.edu \\ 3) Distinguished Professor, Mechanical Engineering, Oulu University, Finland.
}

(Received on June 19, 2009; accepted on October 2, 2009)

\begin{abstract}
Microstructure and mechanical properties of two high Al, low-Si TRIP steels with different $\mathrm{Cr}$ and Mo contents were studied using continuous galvanizing line (CGL) laboratory simulation. Combined use of specific etching methods, optical and electron microscopy observations and EBSD characterization led to verify the epitaxial growth of ferrite during cooling at a moderate rate from the intercritical annealing to the isothermal holding temperature. The amounts of "new" ferrite formed during cooling and retained austenite obtained after processing are much higher in the steel with lower content of hardenability-promoting elements. Measured tensile properties and mechanical behavior of the steel strongly depend on the amount of new ferrite and retained austenite. It is found that the formation of new epitaxial ferrite from intercritical austenite can effectively contribute to the chemical and particle size stabilization of untransformed austenite as well as to obtain the desired TRIP effect under processing conditions highly compatible with industrial practice, i.e. cooling rates near $15^{\circ} \mathrm{C} / \mathrm{s}$ and isothermal holding times at $460^{\circ} \mathrm{C}$ shorter than $60 \mathrm{~s}$.
\end{abstract}

KEY WORDS: TRIP steel; aluminum; continuous galvanizing; new ferrite; retained austenite; mechanical properties.

\section{Introduction}

Thanks to their excellent combination of large uniform elongation and high strength, low-carbon transformationinduced plasticity (TRIP) steels have been used in several applications in the automotive industry. ${ }^{1-3)}$ Conventional cold rolled TRIP steels were firstly developed from CMnSi grades, ${ }^{4-6)}$ but Si greatly impairs galvanizability so efforts have been made in the last years to partially replace Si by other elements that also facilitate the stabilization of retained austenite such as $\mathrm{Al}^{7,8)}$ It has been found that high Al-low Si TRIP steels can be successfully galvanized. ${ }^{8)}$ The traditional concept of the heat treatment for TRIP steels manufacturing associates austenite stabilization (decrease in Ms temperature below room temperature) to the enhancement of carbon enrichment by means of carbidefree bainite formation during "isothermal bainitic holding" or austempering in the temperature regime $350-490^{\circ} \mathrm{C}$. $2,9,10$ ) $\mathrm{Si}$ reduces the kinetics of the bainitic transformation considerably $^{11)}$ so long isothermal holding times (IHt) of 3-5 min are usually necessary to obtain the best tensile properties in Si-alloyed TRIP steels ${ }^{5,7,12)}$ and retained austenite (RA) volume fraction passes through a maximum for long times. ${ }^{13)}$ This implies that Si TRIP steels can only be produced on a line with a long over-aging section, in which a long isothermal holding (IH) can be carried out to obtain enough RA for an adequate TRIP microstructure.
However, most of the current continuous galvanizing lines (CGLs) for automotive sheet products do not have these sections. ${ }^{2,7,8,12,14)} \mathrm{Si}$ TRIP steels usually present their optimal balance of properties for isothermal holding temperature (IHT) near $400^{\circ} \mathrm{C},{ }^{5,7,14)}$ but the presence of the $\mathrm{Zn}$ pot limits the temperatures that can be used during $\mathrm{IH}$ to values higher than the temperature of the molten $\mathrm{Zn}$ bath $\left(460^{\circ} \mathrm{C}\right)$. The time spent on $\mathrm{Zn}$ bath temperature is around $15-30$ s. $^{7,15)}$ It is known that long IH times or high temperatures increase the risk of decomposition of the retained austenite into ferrite and carbides. ${ }^{8,9,12,14,16,17)}$ Unlike Si TRIP steels, several authors have pointed that Al TRIP steels only need moderate holding times (less than $60 \mathrm{~s}$ ) at temperatures closer to $\mathrm{Zn}$ bath temperature $\left(450-475^{\circ} \mathrm{C}\right)$ to obtain substantial amounts of RA with a remarkable stability and optimal mechanical properties. ${ }^{9,12,13,15,16,18-21)}$ This represents an important advantage, as efforts are being made to minimize or even to omit the isothermal bainite transformation step ${ }^{22)}$ in order to approach to industrial processing conditions of CGL. On this matter, some authors found that $\mathrm{Al}$ can accelerate the bainite formation. ${ }^{13,23,24)} \mathrm{As}$ a result, it has been suggested that TRIP steels with Al additions could be produced on a CGL without isothermal bainitic transformation section ${ }^{8)}$ or even through continuous cooling. ${ }^{25)}$

It is generally accepted that the cooling rate from the intercritical annealing (IA) to $\mathrm{IH}$ has to be fast enough to 
avoid the formation of carbides (i.e. pearlite and upper bainite). ${ }^{7,26)}$ Furthermore, it is usually assumed that this cooling rate should also prevent the formation of ferrite. The formation of ferrite during a relatively slow cooling reduces the amount of austenite available for bainitic transformation during overaging, as has been confirmed by thermodynamical calculations ${ }^{27)}$ and by dilatometry experiments. ${ }^{28)}$ Then, the so-called "new" ferrite has been usually considered as something "to be avoided" and therefore many authors have used in their studies very high cooling rates $\left(>30^{\circ} \mathrm{C} / \mathrm{s}\right)$ or even quenching to salt baths that hinder austenite transformation during cooling. 1,2,6,9-11,19,24,29,30) However, TRIP steels are usually coated and those cooling rates are much higher than the typical values close to $15^{\circ} \mathrm{C} / \mathrm{s}$ found in industrial continuous galvanizing (CG) lines. ${ }^{7}$ )

There is controversy in the literature about the nature and properties of new ferrite as well as its influence on the stabilization of austenite and final mechanical properties of multiphase steels. Yi et al. ${ }^{31)}$ concluded that "transformed" (new) ferrite forms by means of a nucleation and growth mechanism. However, most authors ${ }^{27,28,32-38)}$ affirm that ferrite formed from intercritically annealed austenite grows epitaxially on the "retained" or "old" ferrite during cooling at medium rates. Compared to full austenitization, the IA can accelerate the formation of new ferrite due to the presence of pre-existing austenite/ferrite phase boundaries. $^{13,39-41)}$ During cooling, these interfaces only need to advance into the austenite because the new (epitaxial) ferrite has the same crystallographic orientation as the untransformed one. Hence, the step of nucleation of ferrite is not required, as new grain boundaries are not formed, resulting in a faster reaction. As a result, even very high cooling rates cannot prevent the formation of considerable amounts of new ferrite (NF) for certain intercritically annealed dual phase (DP) and TRIP compositions. ${ }^{4,13,21,32,35,40)}$

There is also a debate ${ }^{31,42-44)}$ about the mechanical properties of new "epitaxial" ferrite. Fonshtein et al. ${ }^{45)}$ concluded that NF has a positive effect on the ductility of DP ferritic-martensitic steels, but this is a reflection not so much of the intrinsic properties of this ferrite as it is of the phenomena that facilitate the increase in the volume of this structural phase, such as higher IAT and slower cooling rates. Austenite stability is favored by carbon enrichment (chemical stabilization) as well as austenite particle size refinement ${ }^{10,42,46-49)}$ and NF formation can contribute in both aspects. $^{45)}$ Several authors ${ }^{14,21,27,29,34,38,41,42,47,50)}$ have shown that formation of NF during cooling from IAT to IHT (generally considered as epitaxial growth under paraequilibrium conditions) enhances carbon enrichment and subsequent retention of austenite. On the other hand, the austenite particles decrease in size during cooling ${ }^{31)}$ and very stable small retained austenite can be isolated by the local growth of ferrite at the expense of austenite. ${ }^{45,49)}$

Ferrite growth during cooling from IA to IH can represent the first step for the decrease in Ms temperature (austenite stabilization) that is subsequently culminated by bainite formation during the $\mathrm{IH}^{29,46)}$ Processing schedules have been presented where a slow cooling rate (fast enough to avoid pearlite formation) is applied at high temperatures (generally above Ar1) in order to promote additional carbon enrichment thanks to the new ferrite forma- tion. ${ }^{2,4,11,13,37,38,51)}$ Later, at IHT below the $\mathrm{T}_{0}$ temperature, the remaining austenite particles can decrease in size and become further enriched with $\mathrm{C}(\sim 1.5 \mathrm{wt} \%){ }^{2}{ }^{2}$

The amount of ferrite formed during cooling depends on the alloy's overall composition, the microstructure (grain size), the IA parameters and the cooling rate from the intercritical annealing temperature. ${ }^{21)}$ The transformation behavior during cooling is different for Si-, and Al-alloyed TRIP steels and this difference has been related to their diverse influence on the amount and composition of austenite formed during the intercritical anneals. ${ }^{21)}$ For simple $\mathrm{Al} / \mathrm{Si}$ additions, it has been found that Al-alloyed TRIP steels exhibit a higher intensity of ferrite formation. ${ }^{13,52)}$ When CCT diagrams from a typical IAT corresponding to a $50 \% \alpha / 50 \% \gamma$ phase distribution are compared, it has been found that the ferrite "C" curve of $1 \% \mathrm{Al}$ steels appears at much shorter times than in $1 \% \mathrm{Si}$ steels, and the opposite happens for the pearlite curve. ${ }^{53)}$ Ferrite growth is enhanced for increasing $\mathrm{Al} \mathrm{levels,}{ }^{18)}$ especially for the range $(0.7-1.1 \% \mathrm{Al})$ where this occurs regardless of the applied cooling rate. ${ }^{40)}$ Concerning combined additions of Al-Si, Pradhan et al. ${ }^{12)}$ described that increasing Si content in an Al-TRIP steel raised the hardenability and decreased the magnitude of the ferrite transformation on cooling. As a result, the amount of austenite entering the isothermal holding increased and its carbon content decreased.

It has been found that wide variations in the cooling rate do not greatly affect the mechanical properties of Al TRIP steels whereas the balance is significantly worsened for slowly cooled Si-TRIP steels. ${ }^{12,21,22)}$ Besides, Al TRIP steels show very high austenite carbon content even in the beginning of $\mathrm{IH}^{21)}$

Aforementioned results lead to the question whether enhanced ferrite growth during cooling at intermediate cooling rates can be an effective contributor to chemical as well as particle size stabilization of austenite, especially in $\mathrm{Al}$ steels processed under conditions of moderate cooling rate and short IHt at $460^{\circ} \mathrm{C}$. This paper presents the study of austenite decomposition during cooling from IA to IH of two high Al, low-Si TRIP steels with very different $\mathrm{Cr}$ and Mo contents that caused different hardenabilities of intercritical austenite. The formation of NF during cooling at $15^{\circ} \mathrm{C} / \mathrm{s}$ is correlated to the stabilization of RA at the end of processing. A study of final mechanical properties was also carried out and the results will be presented and discussed.

\section{Experimental Procedure}

The chemical compositions of the steels used in this study are shown in Table 1. Two $\mathrm{C}-\mathrm{Mn}-0.1 \% \mathrm{Si}$ high $\mathrm{Al}$ steels were vacuum-melted and rolled using a computer controlled laboratory hot rolling mill. As can be seen, steel $10 \mathrm{C}$ has a slightly higher Al content than steel 12B, but the latter presents higher $\mathrm{Cr}$ and Mo contents that bring about higher austenite hardenability. ${ }^{51)}$ The laboratory heats were hot rolled using standard procedures and coiled at $550^{\circ} \mathrm{C}$. After hot rolling, the steels were cold rolled $60 \%$. The degree of deformation of all steels was carefully controlled to obtain the same amount of cold rolling deformation, as different initial structures result in different reaction kinetics and microstructure evolution during subsequent thermal 
Table 1. Chemical composition of the steels studied (wt\%). Calculated transformation temperatures and Intercritical Annealing Temperature (IAT) used in the tests $\left({ }^{\circ} \mathrm{C}\right)$

\begin{tabular}{|c|c|c|c|c|c|c|c|c|c|c|c|c|}
\hline Steel & $\mathrm{C}$ & $\mathrm{Mn}$ & $\mathrm{Si}$ & $\mathrm{Cr}$ & $\mathrm{Mo}$ & $\mathrm{Ti}$ & $\mathrm{Al}$ & $\mathrm{Nb}$ & $\left({ }^{\circ} \mathrm{C}\right)$ & $\left({ }^{\circ} \mathrm{C}\right)$ & $\left({ }^{\circ} \mathrm{C}\right)$ & $\left({ }^{\circ} \mathrm{C}\right)$ \\
\hline $10 \mathrm{C}$ & 0.146 & 1.485 & 0.107 & 0.025 & 0.162 & 0.027 & 1.202 & 0.029 & 1029 & 700 & 859 & 860 \\
\hline $12 \mathrm{~B}$ & 0.157 & 1.600 & 0.100 & 0.530 & 0.486 & 0.021 & 1.056 & 0.031 & 971 & 703 & 829 & 830 \\
\hline
\end{tabular}

processing. ${ }^{13)}$

JMatPro $^{\mathrm{TM}}$ software $^{54)}$ was used to predict the $\mathrm{A}_{1}$ and $\mathrm{A}_{3}$ phase transformation temperatures, as well as the desired IAT to produce a $50 \%$ ferrite- $50 \%$ austenite phase balance for the steels studied. Continuous cooling transformation (CCT) diagrams obtained from IAT were also simulated using JMatPro ${ }^{\mathrm{TM}}$. The calculated temperatures are shown in Table 1. Samples approximately $25 \mathrm{~mm} \times 10 \mathrm{~mm}$ in size were cut from the cold rolled material. These specimens were used in CGL thermal simulation treatments, which were carried out in a MTS- $458^{\mathrm{TM}}$ unit with a mounted radiation furnace. During these experiments, samples were heated at a constant rate of $3^{\circ} \mathrm{C} / \mathrm{s}$ to IAT, held for $60 \mathrm{~s}$ and cooled at $15^{\circ} \mathrm{C} / \mathrm{s}$ to the IHT of $460^{\circ} \mathrm{C}$, at which the galvanizing of the steel sheet takes place. The variation of the holding time at $460^{\circ} \mathrm{C}$ (IHt) was investigated by using two different times of 30 and $60 \mathrm{~s}$ for both steels. To extend the study, steel 10C was also tested using IHt of $15 \mathrm{~s}$ and $450 \mathrm{~s}$. The values of IAT, cooling rate, IHT and IHt are very close to the typical values found in a CG line. ${ }^{7)}$ A scheme of the thermal treatments is shown in Fig. 1.

In order to evaluate the austenite decomposition during cooling from IAT to IHT and during IH at $460^{\circ} \mathrm{C}$, the described thermal treatments were interrupted at different stages by quenching the sample into ice water. These stages corresponded to the end of IA, the end of cooling from IAT to $460^{\circ} \mathrm{C}$ and the end of IH. Samples air cooled after IH at $460^{\circ} \mathrm{C}$ were also studied. To carry out the microstructural studies, optical microscopy was extensively used. The samples for microstructural observation were prepared by conventional metallographic techniques. Nital and Lepera etchants were used to distinguish the phases present in the samples. Formation of "new ferrite" (NF) during cooling from IA to IH was examined pre-etching with $2 \%$ nital and using a specific tint-etchant of boiling sodium alkaline chromate $^{55,56)}$ with which old ferrite appears grey or dark and new ferrite remains uncolored.

Measurements of volume fractions of microconstituents were carried out by point counting according to ASTM E562 standard and also by using Bioquant Nova Prime ${ }^{\mathrm{TM}}$ software attached to an Olympus ${ }^{\circledR}$ optical microscope. Selected samples were examined with the help of a Philips $\mathrm{XL} 30^{\mathrm{TM}}$ field emission gun scanning electron microscope. Electron Back Scattering Diffraction (EBSD) analysis was used to determine the crystallographic texture and grain boundary misorientation between the different phases. In order to make quantitative determination of the volume fraction of retained austenite present in several samples, magnetometry tests were carried out in a vibrating specimen magnetometer (VSM). This technique provides very

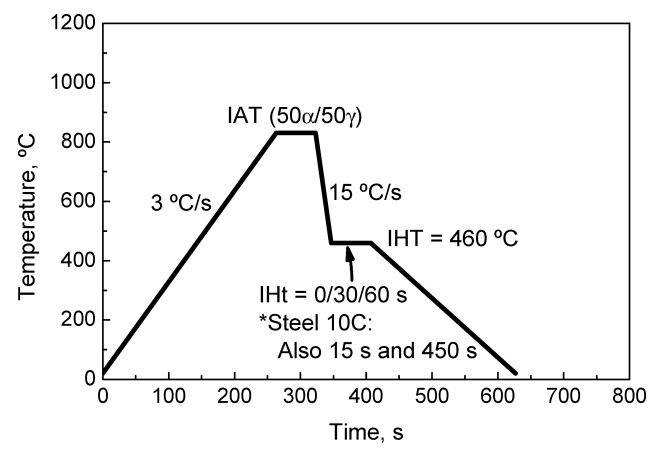

Fig. 1. Thermal schedule of the tests of continuous galvanizing simulation.

good accuracy, as it measures large volumes and thereby overcomes the difficulties of texture effects and local deviations from the averaged quantity of RA. ${ }^{57)} 2.5 \times 2.5 \mathrm{~mm}$ specimens were cut from the samples using a low speed saw. Reference samples were prepared by annealing at $600^{\circ} \mathrm{C}$ for $12 \mathrm{~h}$ under inert atmosphere followed by slow cooling. X-ray diffraction helped to verify the presence of $\mathrm{RA}$ in the heat treated samples as well as the absence of austenite in reference samples for magnetometry. Diffraction experiments were performed using a Philips ${ }^{\mathrm{TM}} \mathrm{X}$-ray diffractometer using $\mathrm{Ni}$ monochromated $\mathrm{Cu}-\mathrm{K} \alpha$ radiation.

In order to evaluate the mechanical properties, $250 \mathrm{~mm} \times$ $50 \mathrm{~mm}$ specimens were annealed in a Gleeble $3500^{\mathrm{TM}}$ unit using the CGL thermal cycles shown in Fig. 1. This large size allows two ASTM sub-size tensile samples of $25.4 \mathrm{~mm}$ nominal gauge length and $6.4 \mathrm{~mm}$ nominal width to be taken from each annealed sheet specimen, as well as samples for metallography. Mechanical testing was performed on a MTS $880^{\mathrm{TM}}$ unit using a strain rate of $2 \mathrm{~mm} / \mathrm{min}$.

\section{Results}

First of all, samples quenched from the end of IA and etched with nital were studied with the optical microscope. The measured volume fraction of martensite (primitive austenite) at this point was close to $61 \%$ in both steels. The difference with the predicted $50 \%$ can be due to small temperature measurement errors together with a slight overestimation in JMatPro ${ }^{\mathrm{TM}}$ calculations of the effect of $\mathrm{Al}$ in increasing transformation temperatures. These samples were also etched with sodium alkaline chromate (S.A.C.) to confirm the absence of NF areas, as white regions were not found (Figs. 2(a) and 2(c)). Some isolated submicron-sized RA particles were distinguished in SEM (Figs. 2(b) and $2(d)$ ). These particles probably come from primitive isolated cementite/carbide particles finely dispersed in the ferrite grains and have a high stability (low Ms temperature) due to their small size and high solute content in the original austenite..$^{29,42,46,48)}$

Figure 3 shows the microstructure of steel $10 \mathrm{C}$ at the end of cooling from IAT, i.e. in the beginning of IH at $460^{\circ} \mathrm{C}$. Figure 3 (a) shows that consderable amounts of new ferrite (revealed by the white regions in the S.A.C.-etched microstructure) have formed during cooling. Interfaces inside the ferrite grains separating new and old ferrite areas cannot be distinguished either here or in SEM (Figs. 3(b) and $3(\mathrm{c})$ ). This is also confirmed by the EBSD map of Fig. 
3(d) that shows that orientation is kept constant throughout ferrite grains. Likewise, neither high nor low-angle grain boundaries are detected between "new" and "old" ferrite areas in Fig. 3(e). On the other hand, SEM images illustrate how NF areas (arrows in Fig. 3(a)) usually surround high carbon $\mathrm{M} / \mathrm{A}$ particles (revealed by the brightest white tones in SEM). This is confirmed in EBSD phase-map of Fig. 3(f), where RA is detected in zones adjacent to NF. In fact, $\mathrm{NF}$ areas always appear in contact with M/A particles, i.e. isolated white regions inside brown-dark "old ferrite" areas were not observed under the optical microscope (Fig. 3(a)).
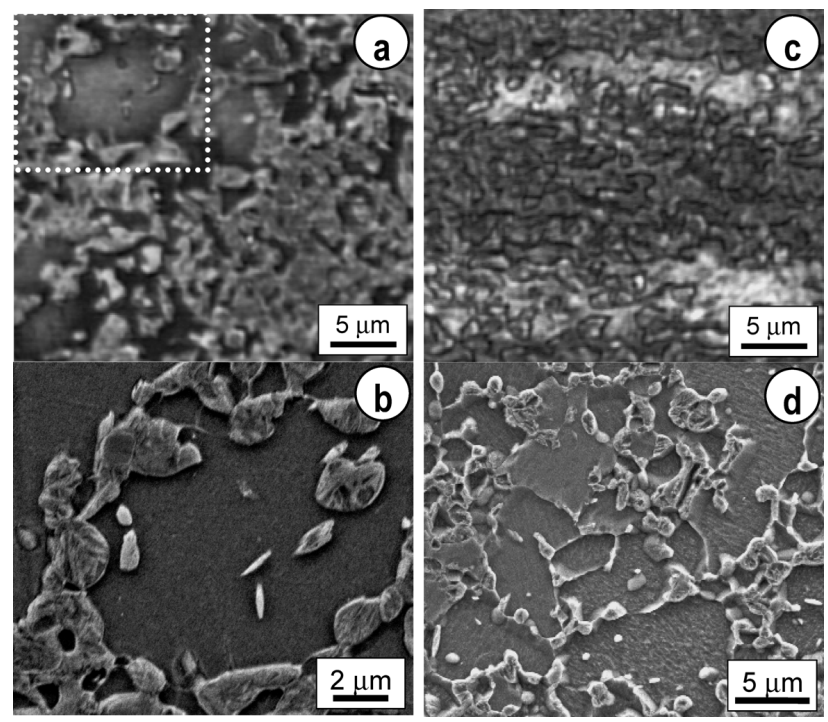

Fig. 2. Microstructure at the end of intercritical annealing (IAt $=60 \mathrm{~s}$ ). (a) Steel $10 \mathrm{C}, \mathrm{IAT}=860^{\circ} \mathrm{C}$, etching: sodium alkaline chromate (S.A.C.); (b) SEM image of detail area marked in a); (c) steel $12 \mathrm{~B}$, IAT $=830^{\circ} \mathrm{C}$, S.A.C.; (d) SEM image of steel 12B.
All these observations, together with the absence of white zones in Figs. 2(a) and 2(c) suggest that areas that remain uncolored after S.A.C etching represent an austenite decomposition product which is very likely NF formed by extensive epitaxial growth during cooling at $15^{\circ} \mathrm{C} / \mathrm{s}$ from IAT to IHT.

The microstructure of steel 12B after quenching under similar conditions to steel $10 \mathrm{C}$ is shown in Fig. 4. It can be seen that NF is hardly detected in this case (Fig. 4(a)). Martensite presents a marked substructure in SEM (Fig. 4(b)), typical of low carbon contents, ${ }^{40)}$ and retained austenite or M/A particles are scarce. As in the case of steel 10C, orientation changes or low angle grain boundaries inside ferrite grains were not detected (Fig. 4(c)).

The fraction of NF was measured by quantitative metallography in samples corresponding to different steps of $\mathrm{CG}$ line. As can be expected, the fraction of $\mathrm{NF}$ grows during cooling and does not vary during $\mathrm{IH}$ at $460^{\circ} \mathrm{C}$. Figure 5 shows the different evolution in both steels: about $27 \%$ of $\mathrm{NF}$ is formed during cooling of steel $10 \mathrm{C}$, while steel $12 \mathrm{~B}$ presents less than $4 \%$ of NF (i.e. about $6 \%$ of intercritical austenite transformed to epitaxial ferrite), as a result of its much higher content in hardenability-promoting elements such as $\mathrm{Cr}$ and Mo. Results for 10C represent about $42 \%$ of original intercritical austenite. This value is slightly lower than results found by other authors in analogous Al-steels processed under comparable conditions ${ }^{40,52)}$ but it is higher than the results found for $1.5 \% \mathrm{Si}$-alloyed steels. ${ }^{27,52)}$

Samples quenched from temperatures corresponding to the end of IA and the beginning of IH were etched with Lepera reagent. The amount of ferrite (that appears brown in this etching) was quantified and the total amount of ferrite formed during IA-IH cooling was measured. It resulted that a total of $31 \%$ of ferrite is formed during cooling in
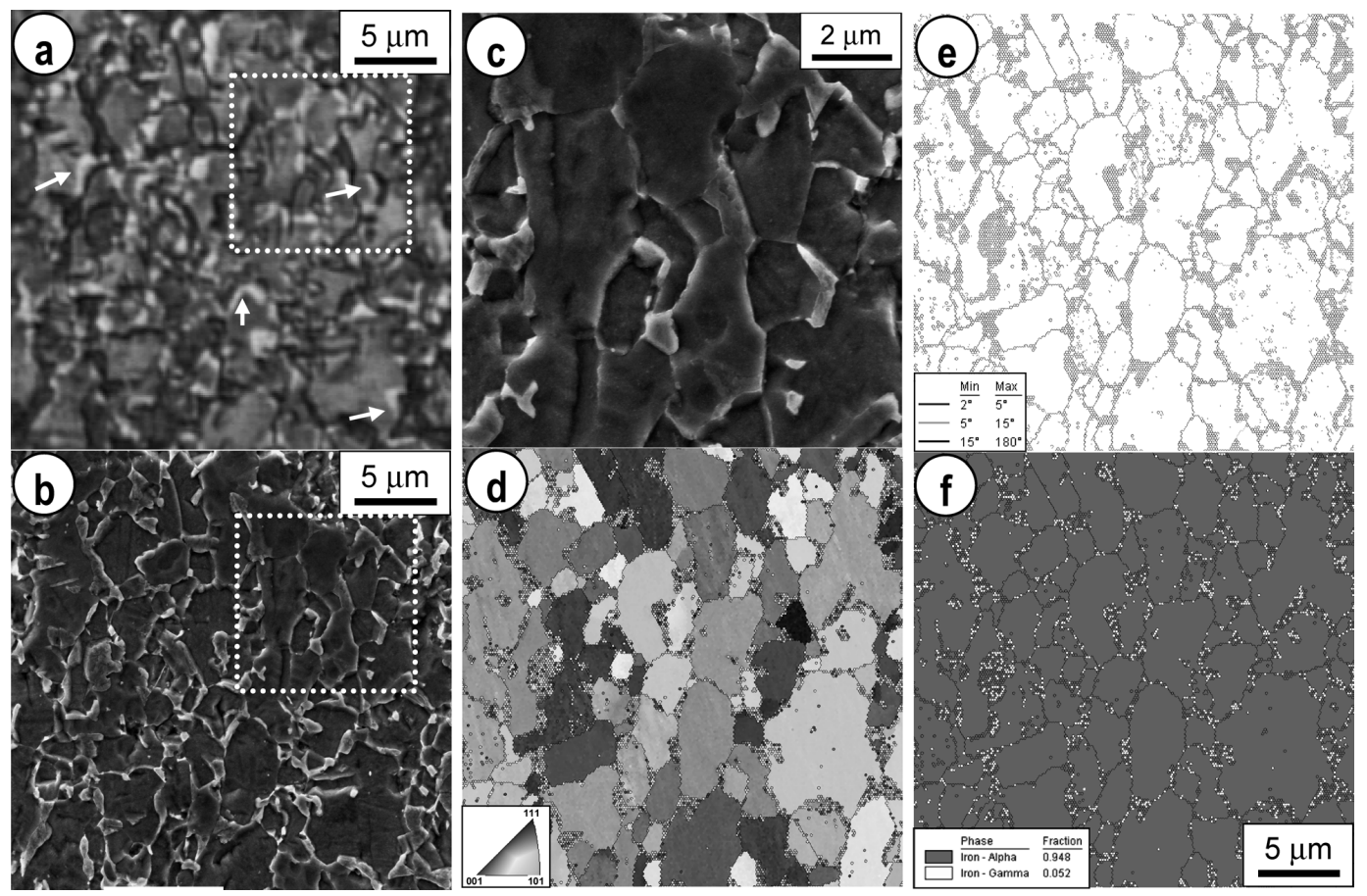

Fig. 3. Microstructure of steel $10 \mathrm{C}$, cooled at $15^{\circ} \mathrm{C} / \mathrm{s}$ from 860 to $460^{\circ} \mathrm{C}$ and immediately quenched (IHt $=0 \mathrm{~s}$ ). (a) $\mathrm{Mi}-$ crostructure taken in optical microscope, S.A.C. etching. Arrows indicate new ferrite areas (white) surrounding M-A particles; (b) SEM image of a); (c) detail marked in a) and b); (d, e, f) maps from EBSD analysis: d) Inverse pole figure; e) grain boundaries; f) phases. 


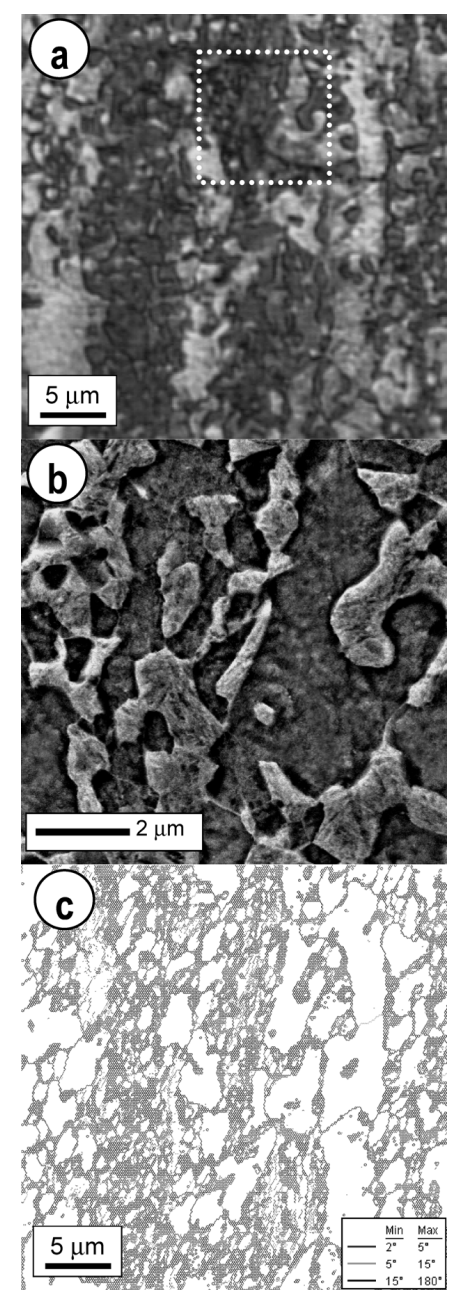

Fig. 4. Microstructure of steel $12 \mathrm{~B}$, cooled at $15^{\circ} \mathrm{C} / \mathrm{s}$ from 830 to $460^{\circ} \mathrm{C}$ and immediately quenched $(\mathrm{IHt}=0 \mathrm{~s}$ ). (a) Microstructure taken in optical microscope, S.A.C. etching; (b) SEM image of detail marked in a); (c) EBSD map showing grain boundaries.

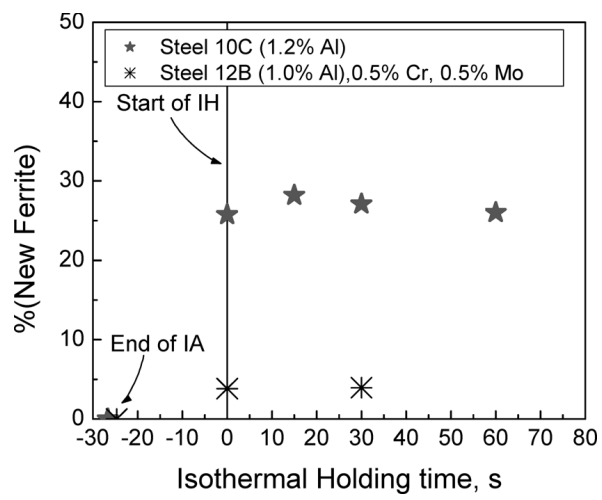

Fig. 5. Determination of the volume fraction of new ferrite formed during cooling from IA to IH and during IH at $460^{\circ} \mathrm{C}$.

steel $10 \mathrm{C}$, whereas $18 \%$ of NF is found in steel 12B. Taking into account the results of S.A.C. etching, this means that the amounts of nucleated new ferrite in steel $10 \mathrm{C}$ and $12 \mathrm{~B}$ would be respectively equal to $4 \%(31-27 \%)$ and $14 \%$ $(18-4 \%)$. These values respectively correspond to about $7 \%$ and $23 \%$ of the intercritical austenite. The CCT diagrams simulated with JMatPro ${ }^{\mathrm{TM}}$ (Fig. 6) help to explain the different values of epitaxial growth, nucleated ferrite

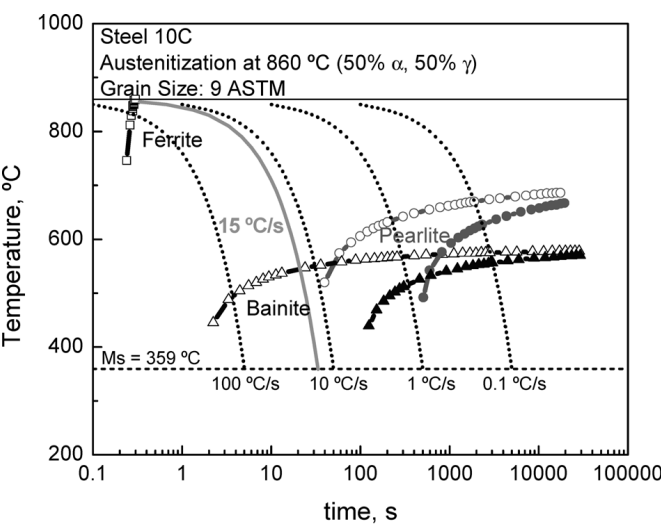

a)

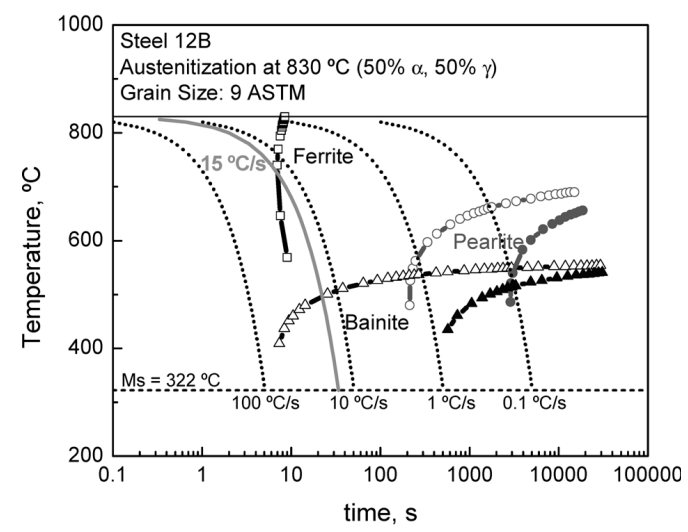

b)

Fig. 6. Continuous cooling transformation (CCT) diagrams. (a) Steel 10C; (b) steel 12B.

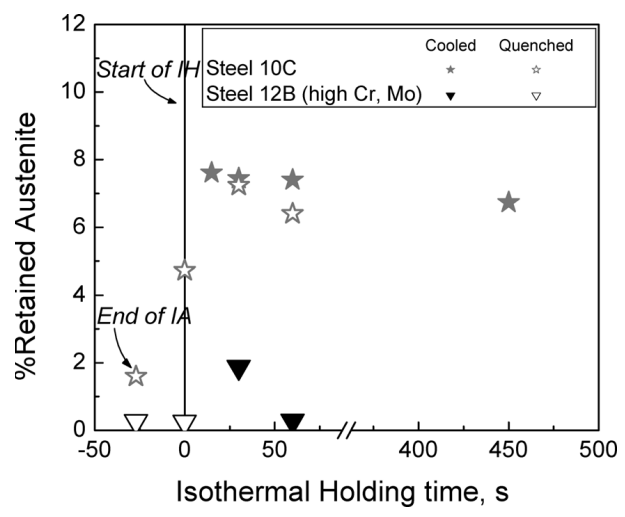

Fig. 7. Determination of the volume fraction of retained austenite formed during cooling from IA to $\mathrm{IH}$ and during $\mathrm{IH}$ at $460^{\circ} \mathrm{C}$.

and total amount of NF found in both steels. It can be seen that using a cooling rate of $15^{\circ} \mathrm{C} / \mathrm{s}$ new ferrite would start to form in steel $10 \mathrm{C}$ immediately after intercritical reheating and from temperatures near $860^{\circ} \mathrm{C}$. However, NF would form in steel $12 \mathrm{~B}$ more than one order of magnitude later and from lower temperatures, i.e. about $725^{\circ} \mathrm{C}$, near the $\mathrm{Ar} 1$ temperature. It can be expected that ferrite growth is more enhanced in the case of steel $10 \mathrm{C}$ compared to the case of steel $12 \mathrm{~B}$. In steel 12B, the lower transformation temperature (more pronounced undercooling) would cause a higher rate of nucleation of new grains.

Figure 7 shows the RA content measured by magnetometry. As Fig. 2(b) showed, RA can be found in samples of steel 10C quenched after IA, and almost $2 \%$ of RA is ob- 
tained by water-quenching the sample from $860^{\circ} \mathrm{C}$. This means that part of the austenite is already significantly rich in carbon and/or has very fine size at these high temperatures. Most of the austenite is retained during cooling at $15^{\circ} \mathrm{C} / \mathrm{s}$ from IA to $\mathrm{IH}$ (more than $3 \%$ ) and during the first 15-30 s of IH (another 2.5\%). RA content detected in steel $10 \mathrm{C}$ for $\mathrm{IHt}=0 \mathrm{~s}$ (about $5 \%$ ) practically coincides with the value shown in Fig. 3(f) and measured with EBSD. The value of RA $\%$ in steel $10 \mathrm{C}$ remains practically constant and higher than $7 \%$ between $15 \mathrm{~s}$ and $450 \mathrm{~s}$. Despite the relatively high IHT used $\left(460^{\circ} \mathrm{C}\right)$, this result indicates that decomposition of austenite into carbides at long IH times is hindered in this high Al-TRIP steel. This was confirmed by SEM observations on sample tested with $\mathrm{IHt}=450 \mathrm{~s}$ where carbides are not found. Other authors found similar amounts of RA at short times in a $1 \% \mathrm{Al}-0.5 \% \mathrm{Si}$ TRIP steel. ${ }^{20)}$ However, they found that RA fraction increased with time and carbides formed after $120 \mathrm{~s}$ at $465^{\circ} \mathrm{C}$. The higher Si content in this steel could have increased the risk of carbide formation at long IHt and high IHT. ${ }^{12)}$ Additionally it can be seen that the values of RA\% measured in steel $10 \mathrm{C}$ after quenching are slightly lower than the values found in the air-cooled samples. Only a small portion of the austenite (less than 1\%) transforms to martensite during rapid quenching, which denotes a significant stability of austenite at the end of IH. It can be expected that in air cooled condition, this small fraction of austenite would transform to martensite in the early stages of straining so its contribution to elongation would be minor. Therefore, the fully processed steel $10 \mathrm{C}$ would contain austenite particles that have been stabilized at different stages of the CGL route (IA, cooling and $\mathrm{IH}$ ). It is likely that these particles will present heterogeneous chemistry ( $\mathrm{C}$ and $\mathrm{Mn}$ contents), shape and size distribution and will have different stabilities. This is known to be beneficial for steel ductility, as austenite will undergo the martensitic transformation and will provide plasticity over a range of initial strains rather than at one time. ${ }^{42)}$

On the other hand, as happened with NF\%, the evolution of $\mathrm{RA} \%$ during $\mathrm{CG}$ processing of steel $12 \mathrm{~B}$ is different to that of steel $10 \mathrm{C}$. The amount of RA at the end of IA is lower than $1 \%$ and it does not increase during cooling to IH. Final microstructure is similar to a DP steel, as a very low amount of RA is obtained even after an IH of $60 \mathrm{~s}$ at $460^{\circ} \mathrm{C}$. An earlier report described that the observed second phase in steel 12B after IH is mostly martensite. ${ }^{58)}$ Comparison of Figs. 5 and 7 leads to the assumption that a certain correlation exists between NF formation during cooling and austenite stabilization, i.e. the enhanced NF formation during cooling of steel 10C (Al steel with lower $\mathrm{Cr}$ and Mo content) can be an effective contributor to the carbon enrichment and stabilization of austenite in the fully processed material with short IHt. Figure 8 shows another microstructural study of a sample of steel $10 \mathrm{C}$ by optical and scanning electron microscopy. Unlike Figs. 3(b) and 3(c), the slight over-etching with S.A.C. has permitted the identification to be made in the SEM of the zones inside the ferrite grains that appear white or stained (bluish) in optical microscope, i.e. it is possible now to differentiate "old" and "new" ferrite areas without an interface between them. Arrows indicate particles of high-carbon martensite without

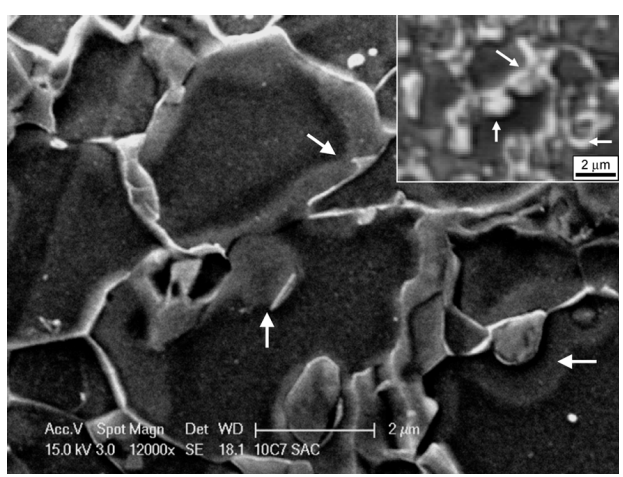

Fig. 8. Microstructure of steel $10 \mathrm{C}$ after $60 \mathrm{~s}$ at $460^{\circ} \mathrm{C}$. S.A.C. etching. Etching time was longer than that used in Figs. 2-4. Arrows indicate new ferrite areas adjacent to retained austenite or high carbon martensite.

visible substructure or probably RA in contact with NF areas. Carbon redistribution from NF growth to austenite has likely originated isolated as well as grain boundary $\mathrm{M} / \mathrm{A}$ particles. Carbon rich $\mathrm{M} / \mathrm{A}$ rims attached to NF can also be detected along grain boundaries or around martensite particles. According to Jeong et al., ${ }^{49)}$ very stable small RA can be isolated by the local growth of ferrite at the expense of austenite. Similarly, Yi et al. ${ }^{31)}$ affirm that austenite particles decrease in size during cooling, so some isolated RA particles can be the remainders of the shrinking sandwiched austenite particles aligned between the "new" and the "old" ferrite. Hence, isolated RA particles like those shown in Fig. 2(b) and Fig. 8 would have different origins. In S.A.C.-etched samples, the latter will appear in optical microscope associated with white NF zones, whereas the former would be isolated within tinted old ferrite areas.

An interesting conclusion about the effect of $\mathrm{Al}$ can be extracted from these results. It has been previously pointed out that $\mathrm{Si}$ decreases martensite start (Ms) temperature but $\mathrm{Al}$ increases it, ${ }^{17,19)}$ i.e. $\mathrm{Al}$ destabilizes the austenite and can move the start temperature and the Ms-Mf range partly above room temperature. ${ }^{2)}$ This can be true for full austenitization, but it is seen that after IA and a moderate cooling rate, the enhanced ferrite growth of Al-TRIP steels ${ }^{13,18,40,53)}$ can originate the carbon enrichment and particle size refinement of the remaining austenite so the Ms temperature is lowered. ${ }^{13,40)}$ For example, Ms values as low as $80^{\circ} \mathrm{C}$ can be obtained in $\mathrm{Al}$ and $\mathrm{Al}-\mathrm{Nb}$ TRIP steels after an IA without $\mathrm{IH}$ in the bainitic range. ${ }^{41)}$

Tensile tests were carried out on fully processed samples of both steels tested with several IHt at $460^{\circ} \mathrm{C}$. The curves shown in Fig. 9 correspond to the processing conditions leading to the best balance of mechanical properties in both cases. Steel 10C displays TRIP behavior with remarkable elongation and good strength, while steel 12B presents a DP-like curve with continuous yielding, high UTS but lower elongation. It should be mentioned that a satisfactory balance of properties (UTS $=770 \mathrm{MPa}$, uniform elongation: $21 \%$, total elongation: $27 \%$ ) was obtained in steel $10 \mathrm{C}$ for an IHt as short as $15 \mathrm{~s}$, i.e. highly compatible with the industrial CGL route. The tensile properties are comparable to the values found by other authors in similar Al TRIP steels processed with faster cooling rates to avoid NF 


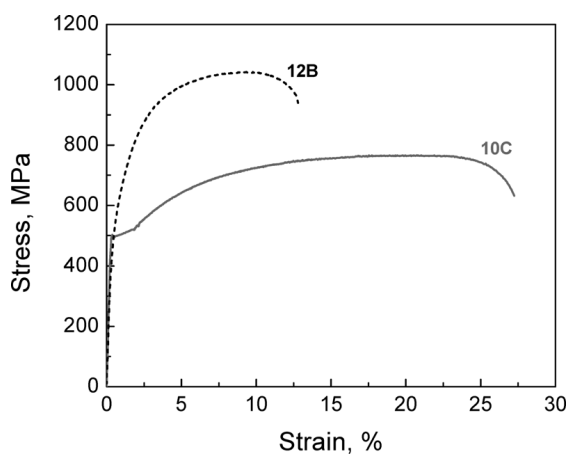

Fig. 9. Stress-strain curves with the best balance of tensile properties. $\mathrm{IHT}=460^{\circ} \mathrm{C}$; steel $10 \mathrm{C}$ : $\mathrm{IHt}=15 \mathrm{~s}$, steel $12 \mathrm{~B}$ : $\mathrm{IHt}=60 \mathrm{~s}$.

and/or considerably longer IHt to maximize bainite fraction. ${ }^{9,13,19,30)}$ When properties of steel $10 \mathrm{C}$ are compared to Si steels processed with similar cooling rate and short IHt, $\mathrm{Si}$ steels usually present higher strengths as a result of stronger solid solution strengthening effect of $\mathrm{Si}^{9,}{ }^{9,12,59)}$ but final balance of properties can be similar as elongation is often poorer. ${ }^{21)}$ Besides, high Si contents would cause the aforementioned galvanizing problems. The results for steel $12 \mathrm{~B}$ with $\mathrm{IHt}=60 \mathrm{~s}(\mathrm{UTS}=1042 \mathrm{MPa}$, U.E.: $10 \%$, T.E.: $13 \%$ ) are very similar to previous observations on high $\mathrm{Cr}$ and $\mathrm{Cr}-\mathrm{Ni}$ steels. ${ }^{60,61)}$ Ehrhardt et al. ${ }^{51)}$ also found that a DP-1000 behavior can be achieved in high Mo steels when short holding times in the bainitic region typical for horizontal CG lines are used. Finally, Fig. 10 shows again the remarkable difference between both steels, now in terms of strain-hardening behavior. Coefficient $n$ of steel 12B sharply decreases with increasing strain, whereas $n$-value in steel 10C is much more stable. As a result, a larger uniform elongation is obtained in steel $10 \mathrm{C}$.

According to the references and to the results of the present study, it can be deduced that Al TRIP steels could present the practical advantage of a higher compatibility with industrial CG processing than Si steels. The enhanced epitaxial growth of NF during IA-IH cooling of Al steels causes particle size stabilization and helps to increase the carbon content of the untransformed austenite in the early stages of austempering. Based on these observations the optimal IHt to get sufficient carbon-rich RA for TRIP effect could be shortened to times closer to CGL practice. In addition, the risk of carbide formation is restrained in Al TRIP steels. Furthermore, the chance of pearlite or carbide formation at relatively slow cooling rates is also lower in $\mathrm{Al}$ steels so cooling rates near $15^{\circ} \mathrm{C} / \mathrm{s}$ and IHT about $460^{\circ} \mathrm{C}$ could be more easily applied. This would apply to compositions such as steel 10C. However, steel 12B (with much higher hardenability caused by higher $\mathrm{Cr}$ and Mo levels) has low amount of RA and it is similar to a DP steel. In this case, the restricted NF formation leads to a poorly stabilized austenite that transforms to a large extent to martensite during final cooling after IH. Similar results and conclusion have been presented by other authors. ${ }^{62)}$ Steel 12B would probably need a different cooling route or a longer IHt to get sufficient bainite formation and a higher fraction of stable RA for TRIP effect. Then, it seems that the enhancement or restriction of NF formation might be used as a controlling factor for final microstructure (amount of re-

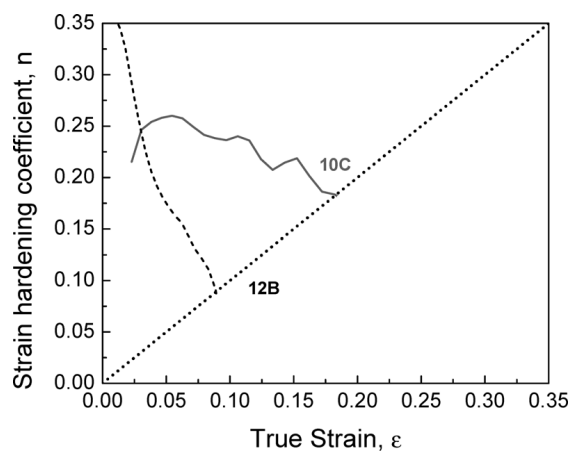

Fig. 10. Strain-hardening coefficient $(n)$ as a function of true strain. $\mathrm{IHT}=460^{\circ} \mathrm{C}$; steel $10 \mathrm{C}$ : $\mathrm{IHt}=15 \mathrm{~s}$, steel $12 \mathrm{~B}$ : $\mathrm{IHt}=60 \mathrm{~s}$.

tained austenite) and mechanical properties of multiphase steels. Several factors that are known to affect intercritical austenite dispersion or NF formation kinetics might be modified: IA conditions, content of hardenability-promoting or new ferrite-enhancing elements, ${ }^{52,62)} \mathrm{Nb}$ microalloying that helps to refine austenite and can promote $\mathrm{NF}^{41,63)}$ value of the cooling rate to get optimal microstructure and properties, ${ }^{5,14)}$ application of complex cooling paths with variable cooling rates ${ }^{4,51)}$ or even application of intercritical deformation. $^{35,43,44,64)}$

\section{Summary and Conclusions}

Microstructure and mechanical properties of two high $\mathrm{Al}$, low-Si TRIP steels with different $\mathrm{Cr}$ and Mo contents were studied during CGL laboratory simulation. Combined use of specific etching methods, optical and electron microscopy and EBSD characterization led to verify the epitaxial growth of "new" ferrite during cooling at $15^{\circ} \mathrm{C} / \mathrm{s}$ from the intercritical annealing to the isothermal holding temperature $\left(460^{\circ} \mathrm{C}\right)$. The following conclusions were obtained:

(1) In the steel with lower hardenability (10C), about $42 \%$ of intercritical austenite transforms to epitaxial ferrite (new ferrite growth) during cooling to IHT. Only 6\% of austenite transforms to epitaxial ferrite in the steel with higher $\mathrm{Cr}$ and Mo contents (12B). In contrast, the nucleation of new grains of ferrite is favored in steel $12 \mathrm{~B}$.

(2) Samples of steel 10C quenched at the beginning of IH show numerous M/A particles adjacent to epitaxial ferrite areas. Steel 12B presents a microstructure with high amount of low carbon martensite.

(3) The volume fraction of retained austenite measured by magnetometry in steel $10 \mathrm{C}$ increases from $2 \%$ to more than $5 \%$ during cooling from IA to $\mathrm{IH}$ and it grows an additional $2.5 \%$ during the first $15-30 \mathrm{~s}$ of IH. RA\% remains practically constant and higher than $7 \%$ between $15 \mathrm{~s}$ and $450 \mathrm{~s}$, indicating low tendency to decomposition of austenite into carbides at long $\mathrm{IH}$ times. On the other hand, RA content measured in steel 12B at successive stages of CGL stays below $2 \%$.

(4) Tensile properties and mechanical behavior of processed samples strongly depend on the amount of new ferrite and retained austenite. For the highest $\mathrm{Cr}$ and Mo content, the behavior is similar to a DP steel with UTS higher than $1000 \mathrm{MPa}$ and decreasing $n$-coefficient, 
whereas steel 10C shows much higher elongation at the expense of some strength decrease as a result of its larger amount of retained austenite.

(5) According to the results of this study, new epitaxial ferrite formed during cooling of the intercritical austenite can effectively contribute to the chemical and particle size stabilization of untransformed austenite. More importantly, this can help to obtain the TRIP effect under processing conditions highly compatible with industrial practice, i.e. intermediate cooling rates near $15^{\circ} \mathrm{C} / \mathrm{s}$ and isothermal holding times at $460^{\circ} \mathrm{C}$ shorter than $60 \mathrm{~s}$.

\section{Acknowledgement}

Dr. Gomez acknowledges financial support of his Postdoctoral Fellowship in BAMPRI, University of Pittsburgh from the Spanish Ministry of Education and Science and to the Fulbright Scholar Program. The authors are also grateful for the financial support of this work by BAMPRI and its industrial and governmental sponsors. The in-kind support of the Research and Technology Center of United States Steel Corporation in Munhall, PA is gratefully acknowledged.

\section{REFERENCES}

1) P. J. Jacques, E. Girault, P. Harletz and F. Delannay: ISIJ Int., 41 (2001), 1061

2) B. C. De Cooman: Curr. Opin. Solid State Mater. Sci., 8 (2004), 285.

3) H. Hofmann, D. Mattissen and T. W. Schaumann: Steel Res. Int., 80 (2009), 22

4) O. Matsumura, Y. Sakuma and H. Takechi: Trans. Iron Steel Inst. Jpn., 27 (1987), 570.

5) Y. Sakuma, O. Matsumura and H. Takechi: Metall. Mater. Trans. A, 22A (1991), 489

6) M. De Meyer, D. Vanderschueren and B. C. De Cooman: ISIJ Int., 39 (1999), 813

7) B. Mintz: Int. Mater. Rev., 46 (2001), 169.

8) J. Mahieu, B. C. De Cooman, J. Maki and S. Claessens: Iron Steelmaker, 29 (2002), 29.

9) E. Girault, A. Mertens, P. Jacques, Y. Houbaert, B. Verlinden and J. V. Humbeeck: Scr. Mater., 44 (2001), 885.

10) M. L. Brandt and G. B. Olson: Iron Steelmaker, 20 (1993), 55.

11) B. C. De Cooman, L. Barbé, J. Mahieu, D. Krizan, L. Samek and M. De Meyer: Can. Metall. Q., 43 (2004), 13.

12) R. Pradhan and J. P. Wise: Proc. 45th MWSP Conf., Vol XLI, ISS Warrendale PA, (2003), 153.

13) N. Fonstein, N. Pottore, S. H. Lalam and D. Bhattacharya: Conf. Proc. Austenite Formation and Decomposition, eds. by E. B. Damm and M. J. Merwin, ISS and TMS, Warrendale, PA, (2003), 549.

14) A. Pichler, S. Traint, G. Arnolder, P. Stiaszny, M. Blamschein and E. A. Werner: Ironmaking Steelmaking, 30 (2003), 21.

15) K. Sugimoto, B. Yu, Y. Mukai and S. Ikeda: ISIJ Int., 45 (2005), 1194.

16) J. R. McDermid and A. Mertens: Iron Steel Technol., 4 (2007), 107.

17) M. De Meyer, J. Mahieu and B. C. De Cooman: Mater. Sci. Technol., 18 (2002), 1121.

18) J. E. Garcia-Gonzalez, C. I. Garcia, M. Hua and A. J. DeArdo: Conf Proc. Materials Science and Technology MS\&T’05, Vol. 2, ed. by R. E. Ashburn, AIST, Warrendale, PA, (2005), 3.

19) J. Mahieu, J. Maki, B. C. De Cooman and S. Claessens: Metall. Mater. Trans A, 33A (2002), 2573.

20) E. M. Bellhouse and J. R. McDermid: Conf. Proc. Materials Science and Technology MS\&T'07, Automotive Symposium, by R. E. Ashburn, AIST, Warrendale, PA, (2007), 295.

21) S. Traint, A. Pichler, K. Spiradek-Hahn, K. Hulka and E. Werner: Proc. Conf. Austenite Formation and Decomposition, eds. by E. B. Damm and M. J. Merwin, ISS and TMS, Warrendale, PA, (2003), 577.

22) W. Bleck and K. Phiu-On: Mater. Sci. Forum, 500-501 (2005), 97.

23) C. Garcia-Mateo, F. G. Caballero and H. K. D. H. Bhadeshia: ISIJ Int., 43 (2003), 1821
24) L. Barbé, K. Verbeken and E. Wettinck: ISIJ Int., 46 (2006), 1251.

25) B. Gajda and A. K. Lis: Journal of Achievements in Materials and Manufacturing Engineering, 20 (2007), 439.

26) K. Hulka, W. Bleck and K. Papamantellos: Proc. 41st MWSP Conf., Baltimore, ISS, Oct. 24-27, (1999), 67.

27) G. Ghosh and G. B. Olson: Metall. Mater. Trans. A, 32A (2001), 455.

28) S. Zaefferer, J. Ohlert and W. Bleck: Acta Mater, 52 (2004), 2765.

29) M. H. Saleh and R. Priestner: J. Mater. Process. Technol., 113 (2001), 587 .

30) A. K. Srivastava, D. Bhattacharjee, G. Jha, N. Gope and S.B. Singh: Mater. Sci. Eng. A, 445-446 (2007), 549.

31) J. J. Yi and I. S. Kim: Scr. Metall., 17 (1983), 299

32) G. T. Eldis: Proc. Symposium Structure and Properties of DualPhase Steels, eds. by R. A. Kot and J. W. Morris, TMS-AIME, Warrendale, PA, (1979), 202.

33) G. S. Huppi, D. K. Matlock and G. Krauss: Scr. Metall., 14 (1980), 1239.

34) W. C. Jeong and C.H. Kim: Scr. Metall., 118 (1985), 37.

35) R. Priestner: Conf. Proc. Phase Transformation '87, ed. by G. W. Lorimer, Institute of Metals, Cambridge, UK, (1987), 411

36) M. Erdogan: J. Mater. Sci., 37 (2002), 3623.

37) A. K. Lis and B. Gajda: Jounal of Achievements in Materials and Manufacturing Engineering, 15 (2006), 127.

38) B. Demir and M. Erdogan: J. Mater. Process. Technol., 208 (2008), 75

39) R. Priestner and M. Ajmal: Mater. Sci. Technol., 3 (1987), 360.

40) O. A. Girina and N. M. Fonstein: Conf. Proc. Materials Science and Technology MS\&T'05, ed. by R. E. Ashburn, AIST, Warrendale, PA, (2005), 65

41) N. Fonstein, O. Yakubovsky, D. Bhattacharya and F. Siciliano: Mater Sci. Forum, 500-501 (2005), 453.

42) N. R. V. Bangaru and A. K. Sachdev: Metall. Trans. A, 13A (1982), 1899.

43) E. Ahmad, M. Sarwar, T. Manzoor and N. Hussain: J. Mater. Sci., 41 (2006), 5417.

44) M. Sarwar, E. Ahmad, K. A. Qureshi and T. Manzoor: Mater. Design, 28 (2007), 335.

45) N. M. Fonshtein and T. M. Efimova: Metallurgist, 50 (2006), 481.

46) H. C. Chen, H. Era and M. Shimizu: Metall. Trans. A, 20A (1989), 437.

47) R. E. Cech and D. Turnbull: Trans. AIME, 206 (1956), 124.

48) J. M. Rigsbee and P. J. Vander Arend: Formable HSLA and Dual Phase Steels, ed. by A. T. Davenport, AIME, New York, (1977), 56.

49) W. C. Jeong and C. H. Kim: Metall. Trans. A, 18A (1987), 933.

50) T. Minote, S. Torizuka, A. Ogawa and M. Niikura: ISIJ Int., 36 (1996), 201.

51) B. Ehrhardt, T. Gerber, H. Hofmann and T. W. Schaumann: Steel Grips, 2 (2004), 247.

52) D. W. Suh, S. J. Park, C. S. Oh and S. J. Kim: Scr. Mater, 57 (2007), 1097.

53) M. Gómez, C. I. Garcia, D. M. Haezebrouck and A. J. DeArdo: ISIJ Int., 49 (2009), 302.

54) Z. Guo, N. Saunders, J. P. Schillé and A. P. Miodownik: Mater. Sci. Eng. A, 499 (2009), 7.

55) D. K. Matlock, G. Krauss, L. F. Ramos and G. S. Huppi: Proc. Symposium Structure and Properties of Dual-Phase Steels, eds. by R. A. Kot and J. W. Morris, TMS-AIME, Warrendale, PA, (1979), 62.

56) R. Lawson, D. Matlock and G. Krauss: Metallography, 13 (1980), 71.

57) R. Petrov, L. Kestens, A. Wasilkowska and Y. Houbaert: Mater. Sci. Eng. A, 447 (2007), 285.

58) M. Gómez, C. I. Garcia, D. M. Haezebrouck and A. J. DeArdo: Conf. Proc. Materials Science and Technology MS\&T'07, Automotive Symposium, ed. by R. E. Ashburn, AIST, Warrendale, PA, (2007), 1.

59) I. Tsukatani, S. Hashimoto and T. Inoue: ISIJ Int., 31 (1991), 992.

60) S. J. Kim, C. G. Lee, T. H. Lee and C. S. Oh: Scr. Mater, 48 (2003), 539.

61) C. G. Lee, S. J. Kim, T. H. Lee and C. S. Oh: ISIJ Int., 44 (2004), 737.

62) D. W. Suh, S. J. Park and S. J. Kim: Metall. Mater. Trans. A, 39A (2008), 2015.

63) K. I. Sugimoto, M. Murata: Conf. Proc. Materials Science and Technology MS\&T'07, Automotive Symposium, ed. by R. E. Ashburn, AIST, Warrendale, PA, (2007), 15.

64) S. Papaefthymiou, W. Bleck, S. Kruijver, J. Sietsma, L. Zhao and S. van der Zwaag: Mater. Sci. Technol., 20 (2004), 201. 